\title{
Changes in mobility and socioeconomic conditions during the COVID-19 outbreak
}

\author{
Marco Dueñas (10 ${ }^{1 凶}$, Mercedes Campi (iD ${ }^{2}$ \& Luis E. Olmos (iD ${ }^{3,4,5}$
}

Since the outbreak of the 2019 novel coronavirus (COVID-19) pandemic, governments have been implementing containment measures aimed at mitigating the spread of the virus, including restrictions to human mobility. The ability to adapt to the pandemic and respond to containment measures can be bound by socioeconomic conditions, which are heterogeneous in large urban areas of low-income and middle-income countries. In this paper, we analyse mobility changes following the implementation of containment measures in Bogotá, Colombia. We characterise the mobility network before and during the pandemic and analyse its evolution and changes between January and July 2020. We observe a general reduction in mobility trends, but the overall connectivity between different areas of the city remains after the lockdown, reflecting the resilience of the mobility network. Then, we estimate a gravity model to assess the effect of socioeconomic conditions on mobility flows. We find that the responses to lockdown policies depend on the socioeconomic conditions of the population. Before the pandemic, the population with better socioeconomic conditions shows higher mobility flows. Since the lockdown, mobility presents a general decrease, but the population with worse socioeconomic conditions shows lower reductions in mobility flows. We conclude by deriving policy implications.

\footnotetext{
${ }^{1}$ Department of Economics, International Trade and Social Policy-Universidad de Bogotá Jorge Tadeo Lozano, Bogotá, Colombia. ${ }^{2}$ CONICET - Universidad de Buenos Aires, Instituto Interdisciplinario de Economía Política de Buenos Aires (IIEP), Buenos Aires, Argentina. ${ }^{3}$ Department of City and Regional Planning, University of California, Berkeley, USA. ${ }^{4}$ National Institute of Health, Bogotá, Colombia. ${ }^{5}$ Facultad de Ciencias Básicas, Universidad de Medellín, Medellín, Colombia. ${ }^{凶}$ email: marcoa.duenase@utadeo.edu.com
} 


\section{Introduction}

ince the outbreak of the 2019 novel coronavirus (COVID19) pandemic, governments have been implementing containment measures aimed at mitigating the spread of the virus. Several policies restricted human mobility, intending to increase social distance, which has effectively slowed transmission. The ability to adapt to the pandemic and respond to containment measures can be bound by socioeconomic conditions, which are heterogeneous in large urban areas of low- and middleincome countries.

There is broad agreement that aggregated mobility data could help fight COVID-19 by providing metrics for data-supported decisions and informing public health actions (Buckee et al., 2020; Oliver et al., 2020). Several studies that use large scale mobile phone or social media data show that mobility has significantly changed during lockdowns in high-income countries (Badr, 2020; Gao et al., 2020, Gatto et al., 2020; Linka et al., 2020; Schlosser et al., 2020). Other studies provide evidence for middle-income countries like China and Brazil (Chinazzi et al., 2020; Coelho et al., 2020; Kraemer et al., 2020). A few studies also show that socioeconomic conditions generate different responses to lockdown policies (Benitez et al., 2020; Bonaccorsi et al., 2020; Fraiberger et al., 2020; Weill et al., 2020).

In addition to the impact on health, the COVID-19 has socioeconomic effects of still unknown magnitude (Nicola et al., 2020; Washington, 2020). The crisis has severely affected labour, increasing unemployment rates and decreasing hours of work and labour force participation worldwide (Béland et al., 2020; del RioChanona et al., 2020). These adverse effects are expected to be unevenly distributed between and within countries. Inequality could spread COVID-19 and, at the same time, the pandemic could exacerbate inequality (Ahmed et al., 2020). Likewise, responses to policies and measures to contain COVID-19 could be different due to existing inequality (Blundell et al., 2020, Bonaccorsi et al., 2020).

In Colombia, "lockdown" policies included border closures and travel bans, public activity restrictions, and school and business closures. The effect of these policies on urban mobility has not been addressed yet. We present evidence for Bogotá, the major urban area and capital of Colombia, with 7.41 million inhabitants, geographically and administratively divided into 20 administrative districts-named localities. Although there have been improvements in recent years, Bogotá is still a city with heavy traffic congestion and a large and chaotic transportation system (Olmos and Muñoz, 2004). The public transport network has over 2.6 million users per day on average and suffers heavy congestion, particularly in rush hours and some locations. The city is also characterised by high levels of income inequality, poverty, and labour informality. Like in other middle-income countries (Ault and Spicer, 2020), subsistence-oriented workers who perform informal activities because of a lack of alternative constitute a large share of the Colombian population (Bernal, 2009).

We analyse mobility flows collected from smart card validations at the integrated public transport system. We contribute with a characterisation of the mobility network before and after the implementation of policies restricting human mobility in a large urban area of a middle-income country. Then, we link changes in mobility flows to socioeconomic conditions to understand if there have been different responses to mobility restrictions.

We observe a general decrease in mobility flows following social distancing interventions on population mobility. However, responses to lockdown policies depend on socioeconomic conditions. In particular, labour informality, poverty, and socioeconomic strata (SES) drive uneven urban mobility changes during the lockdown. Higher SES are consistently associated with larger reductions in mobility. Instead, higher shares of informal workers and a measure of multidimensional poverty are linked to lower decreases in mobility. The general reduction of mobility can be linked to restrictive policies, but self-decisions also drive mobility changes differently depending on restrictions imposed by socioeconomic conditions.

\section{Results}

Mobility networks. We build mobility networks counting the number of smart card validations at the integrated public transport system, which includes Trans-Milenio (TM) - a bus rapid transit (BRT) type of transportation system-and the Integrated Public Transportation System (SITP). We count the number of trips between two stops, defining a trip each time a user makes consecutive validations at two stops. We aggregate trips over working days, and we present mobility data for each calendar week between January 6 and July 17, 2020. To avoid the effect of holidays, the total number of trips for each week is the average of trips between Tuesday and Thursday. We use the week of February 3 as the baseline, which represents normal mobility before the lockdown. We analyse mobility ratios that are defined as the mobility flow in a given week over the mobility flow in the reference week (February 3) in percentage (see the section "Materials and methods" for more details).

Both national and sub-national governments in Colombia implemented several measures to contain the spread of COVID19, prepare the health system, and mitigate the economic and social impact of closure measures. Figure la shows the mobility ratios and the series of measures restricting human mobility in the respective weeks. Mobility flows are lower in the first weeks of the year because of holidays. Thus, we choose February 3 as the reference week as holidays are over for most of the population and schools are opened. Although the first case of COVID-19 in Colombia was detected on March 6, considering the situations in other countries, the government issued non-compulsory requests for remote working to private companies already on February 24, which is associated with a decrease in mobility flows two weeks after the request. Schools, including universities, were closed on March 16, followed by a sharp reduction of mobility flows. The complete lockdown, only allowing essential activities, started on the week of March 23, generating a further decrease in mobility flows on that week $(23.3 \%)$ and reaching a minimum of $16.8 \%$ two weeks after.

The partial lockdown implementation-since April 27-, which allowed a gradual restoration of mobility enabling a set of non-essential activities, is followed by a gradual recovery of mobility flows, reaching a maximum of $36.6 \%$ in the week of July 6. Since June 1, some localities started what we name selected lockdown. Although the city was under partial lockdown, these selected localities returned to complete lockdown. In the period considered, this lockdown was implemented for Kennedy, between June 1 and June 14, and, since July 13 for Santa Fe, Mártires, Candelaria, Ciudad Bolívar, Rafael Uribe Uribe, and Tunjuelito. The selective lockdown is also associated with a decrease in mobility flows.

Bogotá includes 19 urban localities plus one rural, subdivided into 117 Zonal Planning Units (UPZ), which are territorial units for planning urban development at the local level and for defining landuse and urban functions (Fig. 1c). Mobility ratios by localities show a sharp decrease (Fig. 1b). However, mobility reductions reach lower minimum levels in some localities (for example, Usaquén). In comparison, after the lockdown, the mobility recovery rates are roughly similar for most localities, although some localities keep higher mobility ratios (for example, Ciudad Bolívar). A similar pattern is observed for mobility inflows by localities. 

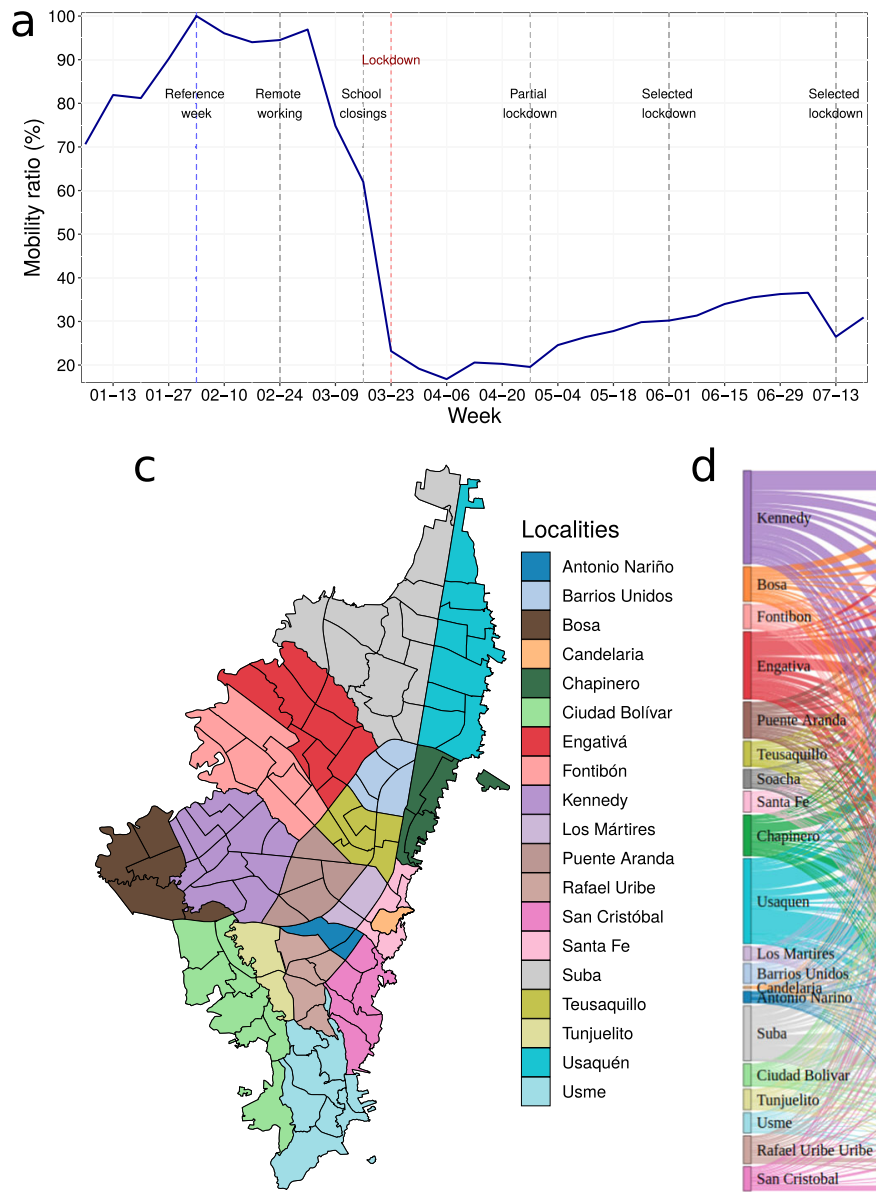

d
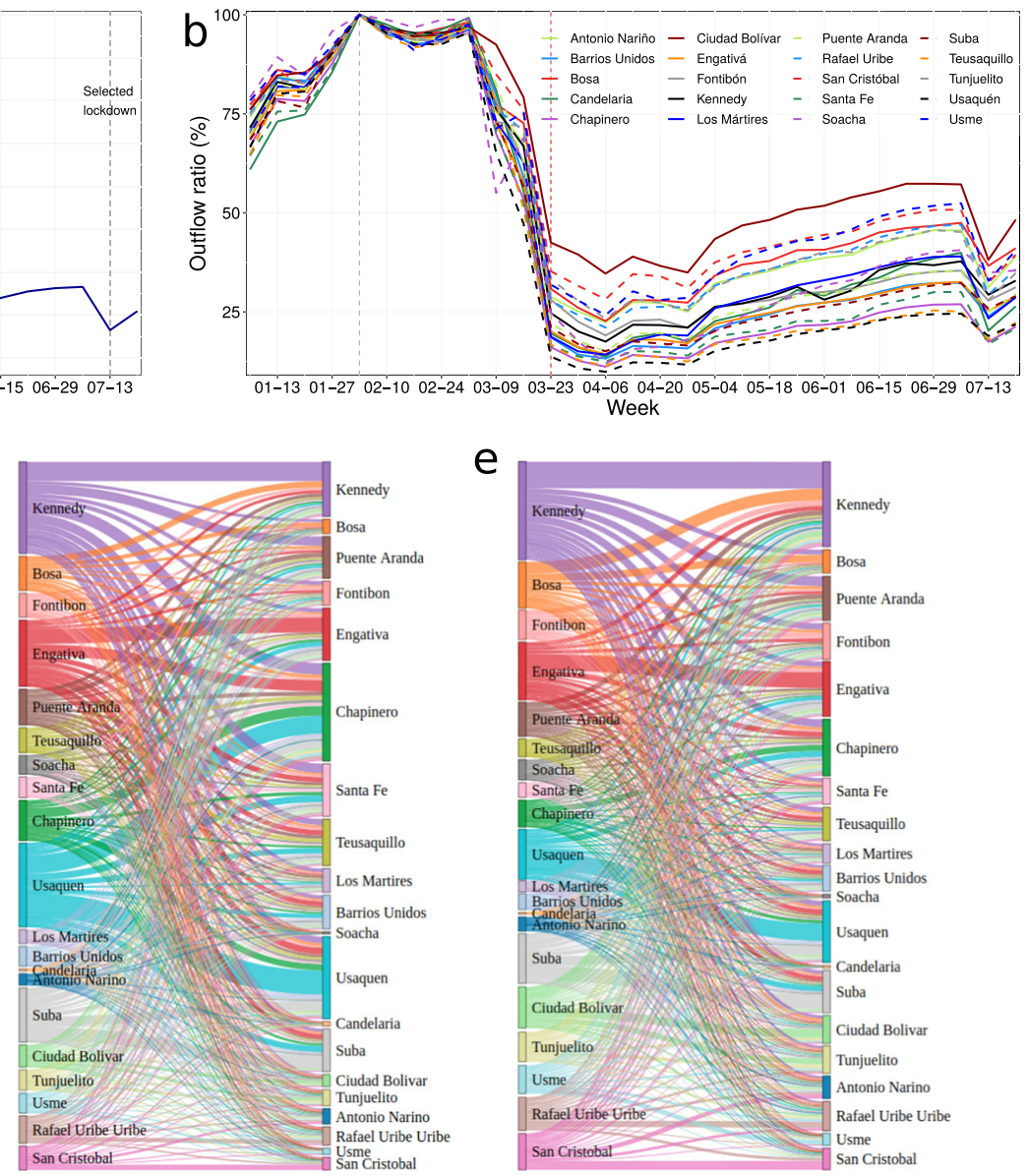

e

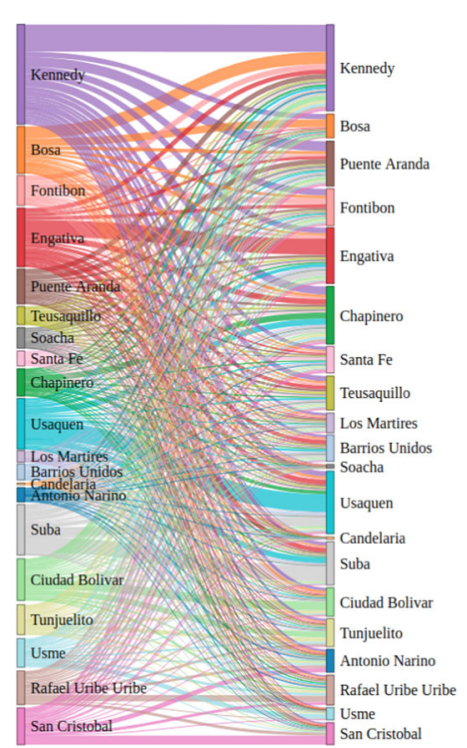

Fig. 1 Evolution of mobility flows in the city of Bogotá. a Total mobility ratio in percentage. Vertical lines indicate the implementation of different policies. b Outflow ratios (\%) for localities. c Map of urban localities and zonal planning units (UPZ). d and e Mobility flows between localities in the reference week (February 3) and in the lockdown (March 23), respectively. Key dates: February 3 the reference week; February 24 requests of remote working for private companies; March 16 schools closing; March 23 implementation of strict lockdown; April 27 partial lockdown; June 1-14, and since July 13 selected strict lockdowns in some localities.

Besides, all localities have flows directed to all other localities indicating that the mobility network is highly connected at the locality level, and the connections between localities survive during the lockdown (see Fig. 1d, e). We observe changes in the relative relevance of localities, comparing the reference week with the lockdown week. Some localities become less relevant, for example, Teusaquillo, Chapinero, and Usaquén, which are central areas that agglomerate services and workplaces. Instead, other localities gain relative relevance. For example, Kennedy, Ciudad Bolívar, Tunjuelito, and San Cristóbal, which include areas of high urbanisation with heterogeneous but, on average, less favourable socioeconomic conditions.

Of course, changes in mobility are very heterogeneous in more disaggregated geographical areas. The maps in Fig. $2 \mathrm{a}-\mathrm{c}$ show mobility outflows at the UPZ level in the reference week, in the lockdown, and the partial lockdown. Figure $2 \mathrm{~d}-\mathrm{f}$ shows mobility networks at the stops-level, before the lockdown (in the reference week, February 3), during the lockdown (March 23), and during the partial lockdown (June 22).

The networks reveal differences between the two types of transportation. The TM shows a massive flow of passengers, while the SITP covers a larger geographical area but transports fewer passengers. They also reveal the importance of the economic centre of the city, located between the TM stops "Avenida Jiménez" (Av Jim) and "Calle 100" (C100), with a distance of over $11 \mathrm{~km}$ between the stops. This central area receives flows from all the geographical areas of the city. Other relevant nodes in the networks are located in areas of high urbanisation. This structure indicates that the population from all areas of Bogotá depend on this central area, which agglomerates economic, financial, health, and marketing activities, to access different types of services.

Comparing mobility networks, we observe that mobility flows drastically decreased in the lockdown week. We observe a substantial reduction in mobility flows, which in the lockdown are $23.2 \%$ of the flows in the reference week (pre-lockdown) (Fig. 2a, b). The gradual reopening of the city leads to a recovery of mobility flows, reaching $35.5 \%$ of the flows observed in the reference week (Fig. 2c).

The mobility network density at the stops-level is low: $2.06 \%$ before the lockdown and $0.78 \%$ in the lockdown, which is not surprising because there are 6197 stops. Instead, the network's density at the level of UPZ reveals a highly connected network. The density decreases from $90.07 \%$ before the lockdown to $81.21 \%$ after the lockdown. Thus, although mobility flows substantially decreased during the lockdown, the connectivity between different areas of the city remained (see Fig. SI 4a, b).

The distribution of time between consecutive smart card validations for all trips is bimodal, with a large concentration of short-lasting trips $(<6 \mathrm{~h})$, and long-lasting trips (between 6 and $16 \mathrm{~h}$ ) in the second mode (Fig. $2 \mathrm{~d}$ ). The probability mass around the first mode is right-skewed, while the second one has a clear central tendency between 10 and $11 \mathrm{~h}$. The shape of the 

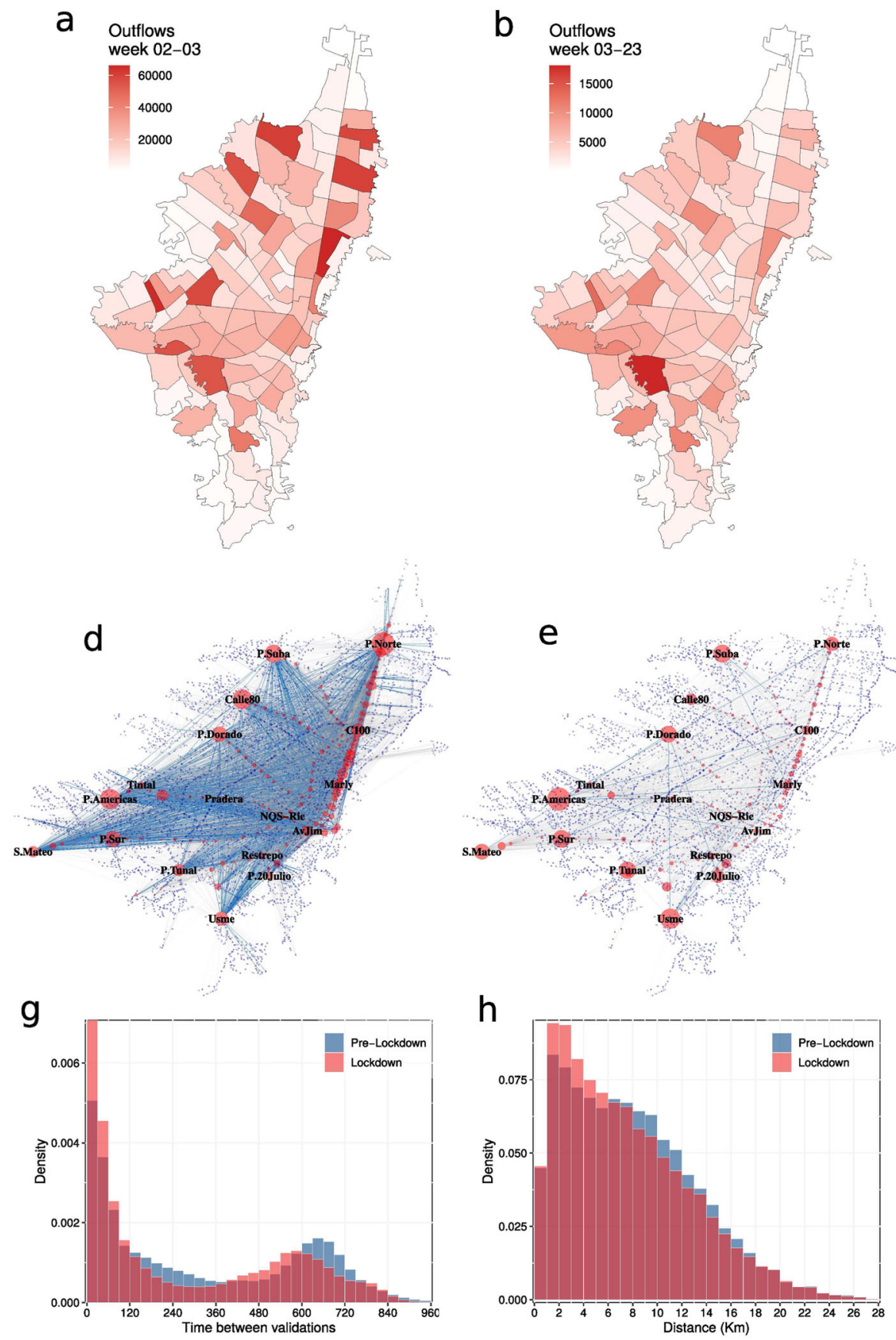
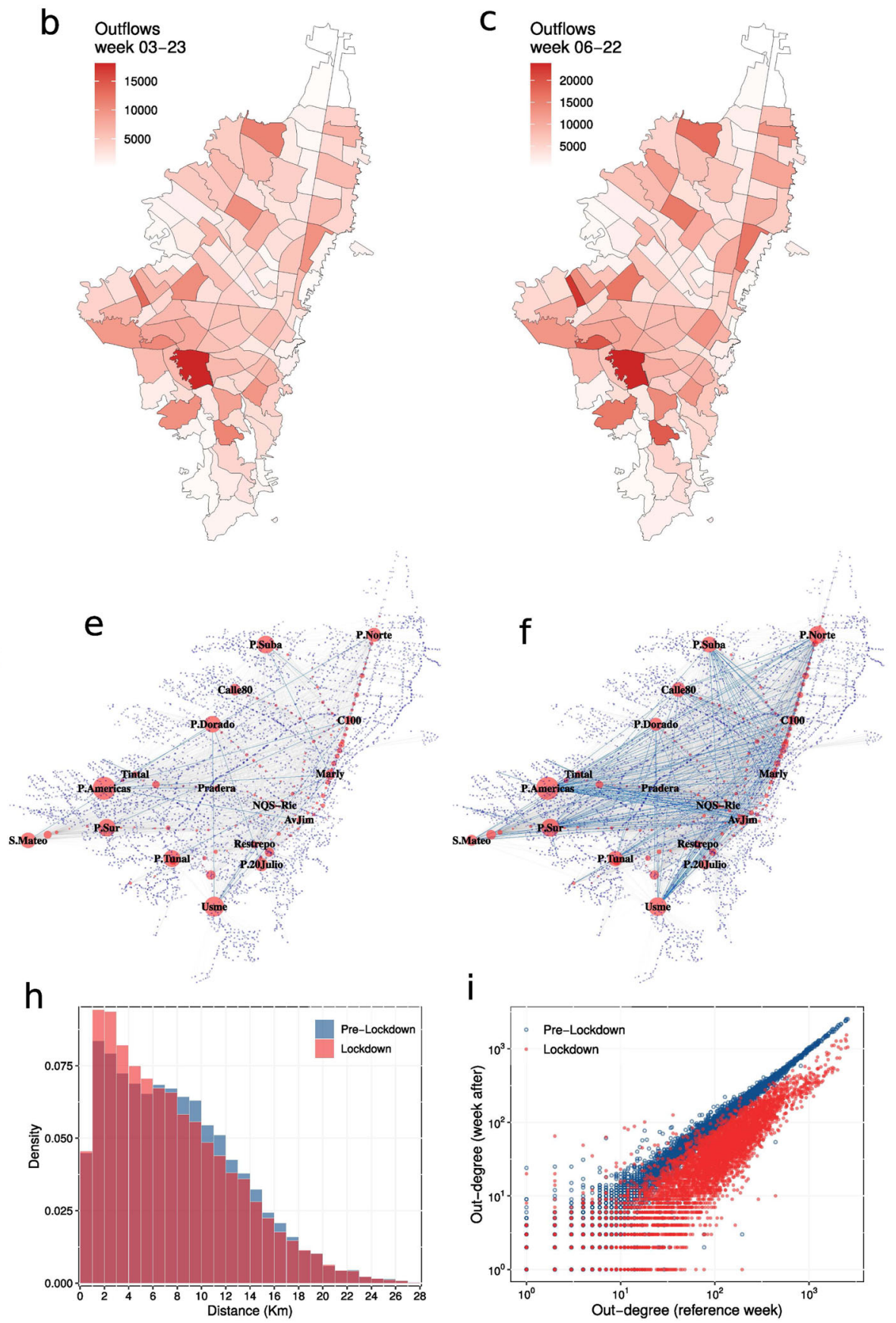

Fig. 2 Changes in mobility flows. a-c Choropleth map of total outflows at UPZ geographical level in different weeks. $\mathbf{d}$-f Mobility networks at the stoplevel. Nodes are bus stops, and edges are the number of consecutive smart card validations observed during a working day. Nodes in blue belong to the SITP, and in red to TM. Link weights $<10$ are filtered out. Link weights $\geq 10$ and $<200$ are in grey. Link weights $\geq 200$ are in blue. Mobility networks in different weeks: pre-lockdown or reference week (February 3), lockdown (March 23), and partial lockdown (June 22), respectively. $\mathbf{g}$ and $\mathbf{h}$ Time and distance distribution, respectively, between smart card validations at the integrated public transport system. Pre-lockdown and lockdown. (i) Correlation between out-degree in the reference week (February 3) and out-degree in pre-lockdown (February 10) and lockdown (March 23).

distribution remains in both periods, although we observe a leftshift of approximately one hour.

The distribution of the distance between consecutive validations is right-skewed, and a critical extent of the probability mass concentrates until $14 \mathrm{~km}$ (Fig. 2e). This evidence reveals that public transport users in Bogotá travel relatively long distances, considering that the city has $1775 \mathrm{~km}^{2}$, and the distance is more extensive from south to north than from west to east. For example, the distance from the historical centre to the largest station at the north (Portal Norte) is $17.8 \mathrm{~km}$, and to the largest station in the south (Portal Sur) is $12.5 \mathrm{~km}$. We observe that users in the long-lasting mode typically travel between 4 and $16 \mathrm{~km}$, while those in the short-lasting mode usually travel shorter distances (Fig. SI.1a, b).

Before the lockdown, $42 \%$ of the distribution of trips are longlasting trips, while in the lockdown, the share decreases to $38 \%$. We assume that the second mode in the distribution of Fig. $2 \mathrm{~d}$ mainly captures workers' trips, considering that the Colombian legal workday has 8 hours and part-time work has $4 \mathrm{~h}$. The decrease in the share of long-lasting trips might reflect that 
several employers implemented remote working systems and that mainly workers in essential activities need to travel during the lockdown. Meanwhile, before the lockdown, $58 \%$ of the trip flows last $<6 \mathrm{~h}$, while after the lockdown, this share reaches $62 \%$ of total flows. This is a piece of interesting evidence given that many essential services, including health care, are not evenly distributed in Bogotá. Therefore, people are constrained to move to access these services. The increase in the relative importance of shortlasting trips reveals that the necessity to travel to access services persists during the lockdown.

The mobility reduction is not only observed in the volume of passengers but also in the number of connections between stops. Figure 2(i) shows the changes in the out-degree (number of destinations) for all the stops in a week of relative normality (February 10) and the week of lockdown (March 23), taking as a reference the out-degree in the reference week (February 3). Before the lockdown, there is a low dispersion between different weeks. Instead, during the lockdown, the dispersion increases. Thus, although many links remain connected, there is a decrease in the number of destinations for practically all stops.

In sum, the mobility network architecture in different periods reveals interesting features, which can have important implications for policy interventions and urban planning. First, the network is highly connected at the UPZ level, indicating the existence of flows between all the zones and localities of the city. Secondly, it shows that despite the sharp decrease in mobility flows during the lockdown, the time and distance distributions remain relatively stable, revealing resilience in trip patterns. Thirdly, changes in urban mobility since the lockdown and subsequent recovery show differences at the UPZ level. Probably, differences in socioeconomic conditions might be driving uneven changes in mobility patterns.

Changes in mobility and socioeconomic conditions. We now analyse the relationship between changes in mobility and indicators of socioeconomic conditions of the population. The correlations between mobility outflows and inflows and the share of informal workers, multidimensional poverty, SES, and vulnerability are very weak for the first weeks of the year (Fig. SI.5a, b). Instead, the correlations become significant and positive with informality and poverty, and significant and negative with SES and vulnerability after the implementation of lockdown policies.

These correlations indicate that the population with informal jobs travels more since the lockdown compared to formal workers. Similarly, higher levels of poverty are associated with higher mobility flows, while higher SES are associated with lower mobility flows. The population classified as vulnerable drastically reduces mobility during the lockdown. Therefore, mobility restriction measures targeting vulnerable populations (for example, strict lockdown for people over 70 years old and people with comorbidities) and self-decision of the vulnerable population might also drive mobility changes.

Figure $3 \mathrm{a}-\mathrm{f}$ shows the correlation between mobility ratio and SES, the share of informal workers, and multidimensional poverty in the week of the lockdown (March 23) and a week during the partial lockdown (June 22). We observe a general decrease in mobility flows. However, the correlations indicate that the reductions depend on socioeconomic conditions. We observe larger reductions in mobility flows for the population with better socioeconomic conditions and the opposite for worse socioeconomic conditions. During the partial lockdown, the gap between reductions in mobility flows for lower and higher SES, poverty, and informal workers share increases, implying that the population with better socioeconomic conditions can maintain lower mobility for a longer time.
We build a gravity model to explore the effect of socioeconomic conditions on mobility flows between different zonal planning units, which allows us to address the heterogeneity in socioeconomic conditions (Fig. 3g-i). We estimate the effects of population, distance, SES, informality, and multidimensional poverty, before and after the lockdown, for all trip flows, longlasting trips, and short-lasting trips (Table SI.3 presents the estimation results).

The results indicate that the geographical distance between the origin and destination has a negative effect on mobility flows, which becomes stronger since the lockdown. Before the lockdown, a higher population in the origin increases mobility. In contrast, the effect of the population in the destination depends on the model and type of trips (short-lasting or long-lasting). In particular, the effect of the population in the destination is negative for long-lasting trips, which are assumed to represent formal workers' trips mainly. The factors attracting flows in the destination are urban amenities, including services and workplaces, which are not necessarily related to the population of the area. In Bogotá, more urbanised zones are not necessarily those with more and better amenities. Since the lockdown, the effect of the origin and destination population is always positive and stronger. Thus, trips are more likely to be observed between more populated zones.

We analyse the impact of three different indicators of socioeconomic conditions (SES, the share of informal workers, and multidimensional poverty) using independent estimations because these variables are highly correlated (Table SI.1). Table 1 shows the differences in the estimated effects on mobility flows for the lowest and highest scores of the socioeconomic variables at the origin and destination, before and after the lockdown, for the mobility network of all trips, and the networks restricted to longlasting and short-lasting trips.

Before the lockdown, better socioeconomic conditions at the origin are always positively associated with mobility flows. Considering all trips, the flows of the lowest strata are 35\% lower than those of the sixth SES. Similarly, zones with the highest shares of informal workers generate $46 \%$ fewer flows than zones with the lowest share of informal workers, and zones with the highest poverty level generate 52\% fewer flows than the zones with the lowest poverty.

The effects of the socioeconomic conditions in the destinations have more considerable differences than the socioeconomic conditions in the origin. We estimate differences in the flows for extreme values of socioeconomic variables in the destination of $-91 \%$ for SES, $-78 \%$ for zones with the highest share of informal workers, and 10 times less for the highest level of poverty.

After the lockdown, we observe that better socioeconomic conditions in the origin lead to a higher mobility reduction for all trips. We estimate that the flows of the lower SES are 54\% larger than those of the sixth SES. Zones with the highest share of informal workers generate $12 \%$ more flows than zones with the lowest informality, and zones with the highest level of poverty have $24 \%$ more flows than zones with the lowest level of poverty. The estimated differences between destination zones with better and worse socioeconomic conditions slightly decrease. Thus, the socioeconomic conditions of the origin are more relevant to explain changes in mobility flows, which can be related to the strong directionality of the network.

The estimated differences for long-lasting and short-lasting flows are also interesting. In particular, long-lasting trips reveal that the changes in mobility patterns can be larger for the zones with low SES or with higher shares of informal workers. Assuming that mainly formal workers are those explaining long-lasting trips, these larger differences might derive from differences in the feasibility of working from home. 
a

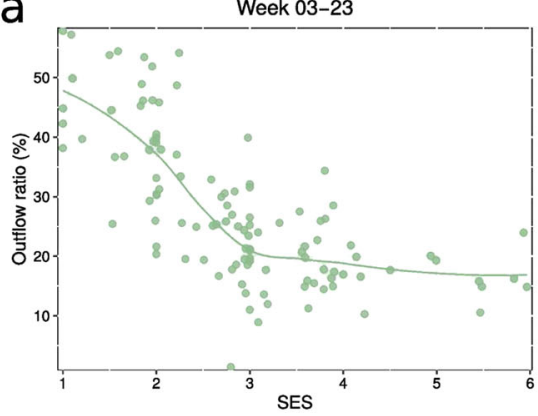

d

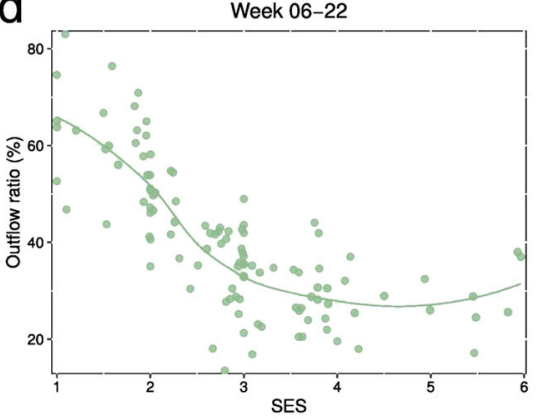

g

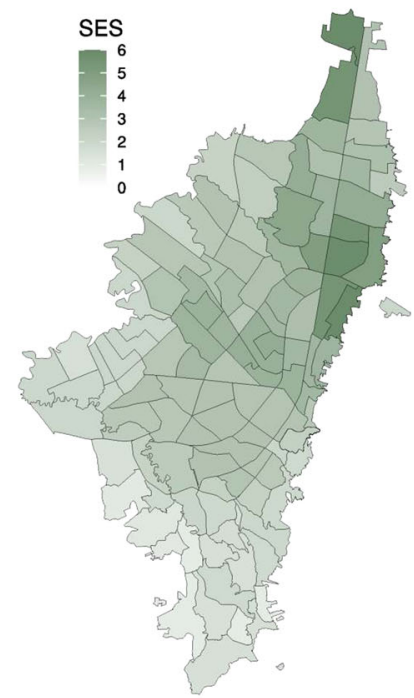

b

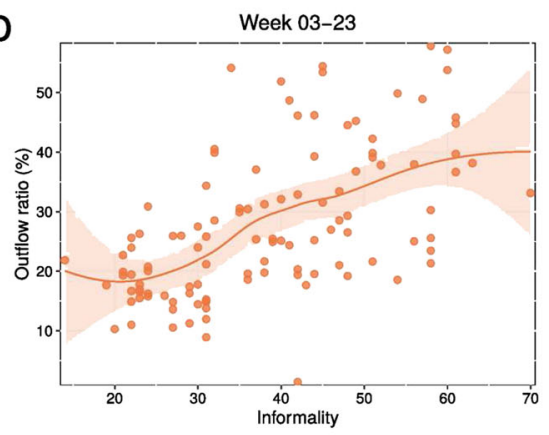

e

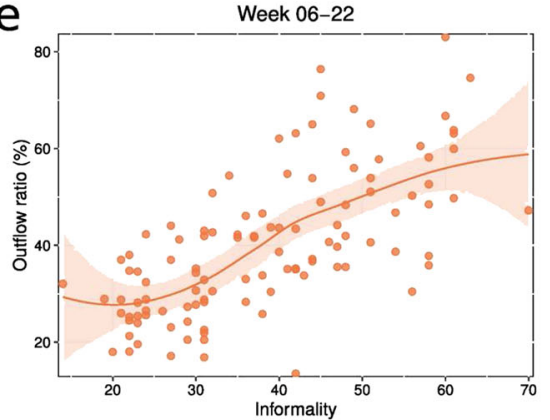

h

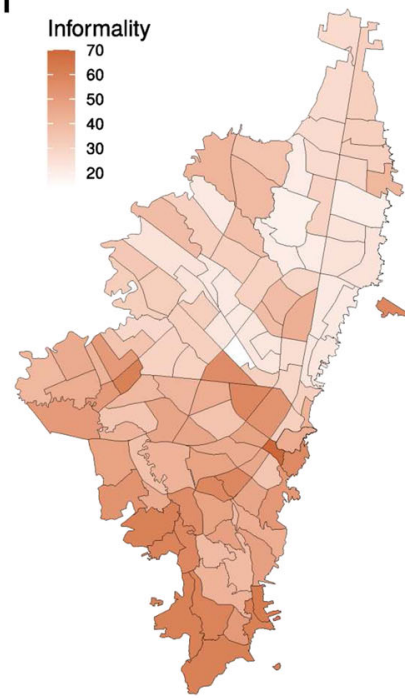

C

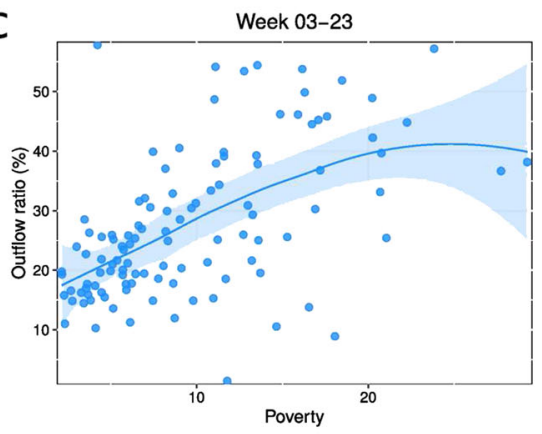

f

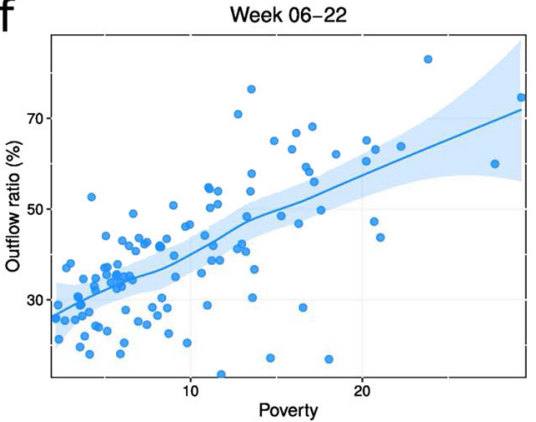

i

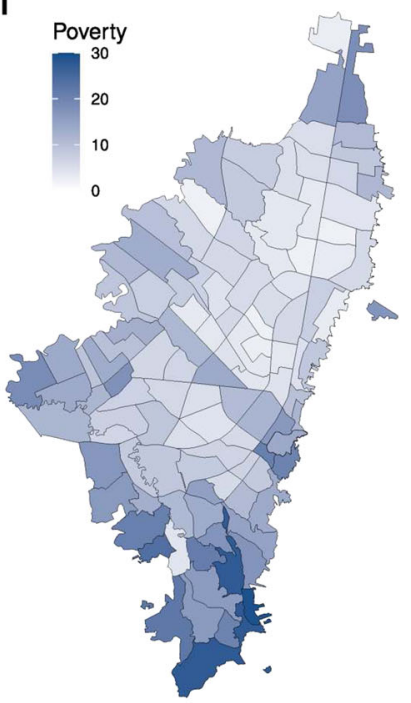

Fig. 3 Changes in mobility and socioeconomic conditions. a-f Correlations between outflows ratio at the UPZ level with respect to the reference week (February 3) and socioeconomic strata (SES), the share of informal workers, and multidimensional poverty, respectively. $\mathbf{g}$-i Socioeconomic conditions at the UPZ level. Maps exclude rural areas.

Overall, the evidence indicates that the population with better socioeconomic conditions have higher possibilities of decreasing mobility. In contrast, a large share of the population with worse socioeconomic conditions needs to travel despite the measures implemented to restrict mobility. Interestingly, we observe a similar behaviour at the national level.

To assess the mobility change at a municipality level, we leverage the Movement Range Maps released by the Facebook Data for Good program (Maas et al., 2019). Specifically, we use the "Change in Movement" metric that looks at how much people are moving around and compares it to the baseline period, full February 2020 (see the section "Methods"). We thus combine these movement data and the multidimensional poverty index aggregated by municipalities. Figure 4 shows a clear correlation between these two metrics for the lockdown week and the selected week of partial lockdown. In line with what we observed in Bogotá, the wealthiest cities move less than the poorer ones.

\section{Discussion}

Decreasing urban mobility is key to reduce the spread of COVID19. Policies implemented to reduce human mobility and selfdecisions of citizens appear effectively driving changes in the transport system mobility in the city of Bogotá. We observe that, two weeks after the strict lockdown implementation, mobility flows decrease until $16.8 \%$ of the flows observed in the prelockdown period and start gradually recovering during the partial lockdown period until a maximum level of $36.6 \%$ before the application of selected lockdowns. The mobility network is highly connected at the locality and UPZ levels, even during the period 
of lockdown and partial lockdown. The network preserves its main features revealing the resilience of mobility flows and the transportation system.

The average reduction in mobility hides more complex situations related to the ability of the population to respond to social distancing and mobility restriction measures in a middle-income country with high levels of inequality. Changes in mobility are strongly associated with the socioeconomic conditions of the population. Zones with higher poverty, larger shares of informal workers, and lower SES have more moderate mobility reductions during the lockdown than zones with better socioeconomic conditions. This evidence reflects that different socioeconomic conditions imply asymmetries in the feasibility of working from home, using savings, postponing consumption, and, more generally, in the ability to respond to lockdown policies positively. Moreover, we find that the socioeconomic conditions of the origin are more relevant to explain changes in mobility flows, which can be related to the strong directionality of the network.

Before the lockdown, more populated areas generate more mobility flows. Instead, the factors attracting flows in the destination are urban amenities, including services and workplaces, which are not necessarily related to the population of the area. In

\begin{tabular}{|c|c|c|c|c|c|c|}
\hline \multirow[t]{2}{*}{ Variable } & \multicolumn{2}{|c|}{ All trips } & \multicolumn{2}{|c|}{$\begin{array}{l}\text { Long- } \\
\text { lasting trips }\end{array}$} & \multicolumn{2}{|c|}{$\begin{array}{l}\text { Short- } \\
\text { lasting trips }\end{array}$} \\
\hline & Before & After & Before & After & Before & After \\
\hline $\begin{array}{l}\text { SES } \\
\text { Informality } \\
\text { Poverty }_{o} \\
\text { SES }_{d} \\
\text { Informality }_{d} \\
\text { Poverty }_{d}\end{array}$ & $\begin{array}{l}-0.35 \\
-0.46 \\
-0.52 \\
-0.91 \\
-0.78 \\
-10.81\end{array}$ & $\begin{array}{r}0.54 \\
0.12 \\
0.24 \\
-0.85 \\
-0.57 \\
-10.74\end{array}$ & $\begin{array}{l}-0.08 \\
-0.43 \\
-0.59 \\
-0.94 \\
-0.88 \\
-10.85\end{array}$ & $\begin{array}{c}1.51 \\
0.40 \\
0.18 \\
-0.91 \\
-0.75 \\
-10.83\end{array}$ & $\begin{array}{l}-0.53 \\
-0.52 \\
-0.48 \\
-0.86 \\
-0.67 \\
-10.78\end{array}$ & $\begin{array}{r}0.05 \\
0.18 \\
0.21 \\
-0.78 \\
-0.40 \\
-10.67\end{array}$ \\
\hline
\end{tabular}

Note: The estimated differences are between the SES 1 and 6 , the minimum and maximum shares of informal workers observed ( $14 \%$ and $70 \%)$, and the minimum and maximum levels of poverty observed (2.15 and 29.26). See Tables SI.2 and SI.3.
Bogotá, more urbanised zones are not necessarily those with more and better amenities. Since the lockdown, trips are more likely to be observed between more populated zones.

These results have several policy implications. First, if measures restricting mobility are still necessary to contain the spread of COVID-19 in the near future, the evidence indicates the need for an effective income support policy. Otherwise, social distancing will be difficult to achieve because a relevant share of the population will not be able to respond positively to these measures. For subsistence-oriented informal workers, which can reach $70 \%$ of total workers in some areas, the possibilities of performing remote working or using savings to subsist without working are very limited. In the short-term, an income support policy could help this population, but a medium-term policy seeking to improve general living conditions and reduce inequality is necessary.

Secondly, short-lasting trips show a lower reduction, indicating that not only workers in essential and allowed activities are constrained to move but also other people who probably move to access services, including health care, employment, recreation, and food. A more detailed analysis uncovering the reasons for these trips is necessary. However, different measures could be implemented to reduce this type of flows. For example, decentralise legal and healthcare systems, grant universal internet access, and improve technology platforms to provide online public and private services. In sum, implement policies aiming to redistribute activities so that people can access them without using public transport, this is, by bicycle or on foot (Xu et al., 2020).

Thirdly, the resilience of the mobility network indicates that the unsolved problems of the transport system in Bogotá tend to persist during the lockdown and will return as soon as the system recovers mobility flows. Policymakers and universities are proposing or evaluating possible measures to address these problems, which seems imperative in the context of a gradual reopening of economic activities and mobility. For example, generate alternative transport routes, redistribute the programming of routes to dispatch more buses to areas of high urbanisation and worse socioeconomic conditions, promote the staggering of working hours to reduce congestion, guarantee additional resources to increase frequencies and changes in operation, adopt disinfection practices in stations and buses, facilitate the use of the bicycle providing a connected and well-designed infrastructure, and generate changes in social behaviour (see, for example, Ramirez Varela et al., 2020).
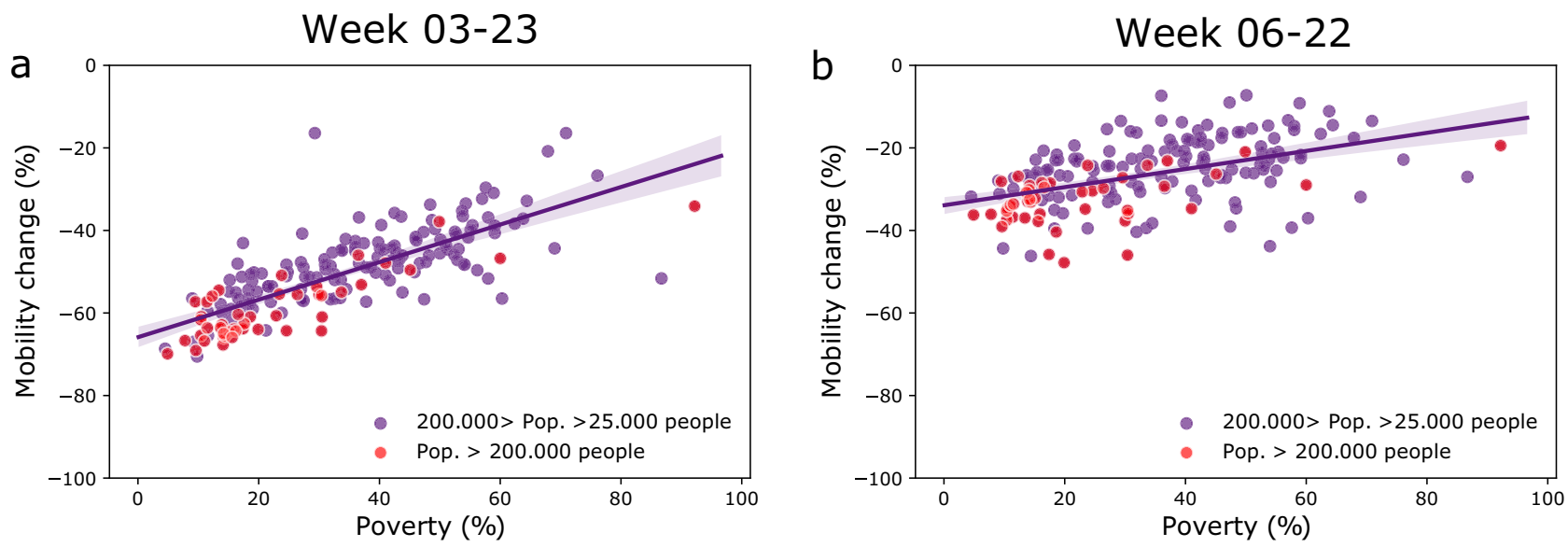

Fig. 4 Mobility changes vs. poverty across the country. We explore the relationship between the variation in mobility and poverty levels at a municipality level for (a) national lockdown week and (b) the selected week of partial lockdown. We distinguish large urban areas with more than 200,000 inhabitants (red) from medium-size towns with more than 25,000 inhabitants (purple). The correlation is good in both cases, and it seems not to depend on the city's size. In the case of partial lockdown conditions, the high dispersion of points can be due to the different lockdown strategies imposed by the local administrations. 
The impact of human mobility and travel restrictions on the spread of COVID-19 has been largely reported in several studies (Gatto et al., 2020; Hadjidemetriou et al., 2020; Kraemer et al., 2020). While intra-city travel reductions have a high impact on overall infection numbers, intercity travel reductions can narrow the scope of the outbreak and help target resources. The empirical evidence presented in this paper shows that high poverty levels in middleincome countries drive non-compliance with lockdown policies and social-distancing. These non-compliance behaviours could prevent the fast and successful containment of the pandemic, as partly observed in Latin America. Future research needs to systematically assess the contributions of these factors in the evolution of disease transmissions and, thus, in how to reduce their impact.

Overall, in a city with significant inequalities, the needs and possibilities of the vulnerable population due to socioeconomic conditions must be addressed to implement successful strategies of social distance and mobility restriction.

\section{Methods}

Income levels of countries. The income level of a country is based on the classification made by the World Bank (see: https:// datahelpdesk.worldbank.org/knowledgebase/articles/906519world-bank-country-and-lending-groups). With a gross domestic product (GDP) per capita of 6428.7 US dollars in 2019, Colombia is classified as an upper-middle income economy (between 4046 and 12,535 US dollars).

Geographical units. Bogotá consists of 19 urban localities plus one rural, which are subdivided into 117 zonal planning units (UPZ). Social and economic conditions are very heterogeneous in Bogotá, and this heterogeneity persists even within UPZ. Despite this, we use the UPZ as our main geographical unit of analysis since, compared to localities, it allows better control of social and economic heterogeneity. Moreover, UPZ are units of interest in urban planning.

Socioeconomic data. Several indicators of socioeconomic conditions in Bogotá derive from geolocated Census data with a high spatial resolution. We use indicators available at the block level and aggregate them at the UPZ level, weighting variables of interest by the population of each UPZ.

Population and SES. We obtain a census population data set at the city block level with their SES. There are around 45,000 blocks classified by SES in the city. This classification has been made according to external conditions and urban surroundings, including the quality of urban spaces and access to goods and services, with stratum from 1 to 6 , representing the resident's income level from low to high (Uribe-Mallarino, 2008). The socioeconomic stratification targets houses instead of families or individuals, and it is defined by a formal body of the Stratification Committee (Gallego et al., 2016). The strata 1, 2, and 3 include $86,04 \%$ of the population, strata 4 includes $9,42 \%$, and the strata 5 and 6 include only $4,54 \%$ of total population (Secretaria Distrital de Planeación, 2017). This data set is used for generating population-weighted SES estimates at the UPZ level.

Multidimensional poverty. Multidimensional poverty has five dimensions (educational conditions, conditions of childhood and youth, health, work, and access to public services and housing conditions) and 15 indicators. All dimensions weigh 20\%, and the indicators have the same weight within their respective dimension. Households are considered poor if they have deprivation in at least $33.3 \%$ of the indicators (DANE, 2020a).
Vulnerability. The indicator of vulnerability is built by determining the share of individuals per block with a set of comorbidities, which are identified as risk factors that can generate complications in people with COVID-19, the share of people over 60 years old and in an overcrowded household or living alone, and population density per block. The indicator is built using the 2018 National Population and Housing Census and the Individual Registry of Health Benefits (DANE, 2020b).

Informality. There are different definitions of informal work. Some of them include: employees and employers working in firms with less than ten workers, unpaid family workers, domestic household workers, and self-employed individuals who are not professionals or technicians; and all employment is not covered by health or pension contributions (Bernal, 2009). Using different definitions, the extent of informality in Colombia has ranged between $60 \%$ and $70 \%$ over the last decades (International Labour Organization (ILO), 2014).

As an effort to characterise informal employment in the city, the District Department of Planning in Bogotá (SDP) has estimated the informality at the UPZ level (Gutiérrez, 2020). Informality is defined as the share of individuals having an occupation with an income but not enrolled in the health system or pension fund (Secretaria Distrital de Desarrollo Económico, 2020).

\section{Mobility data}

Public transport data. We use public transport data from the city of Bogotá. Public bus transportation in Bogotá consists of TM, which is a bus rapid transit (BRT) type of transportation system, and the Integrated Public Transportation System (its acronym in Spanish SITP). According to the Bogotá's transportation company, TM has 143 stations, a coverage of $114.4 \mathrm{~km}$, and 98 bus routes, while the SITP has 7516 stops, a coverage of $1,890.4 \mathrm{~km}$, and 282 bus routes (Transmilenio, 2020).

To access the transport service, each user must validate its smart card-Tullave (which is personal) - at the entrance of each station in TM or a bus in SITP. We use smart card validations at the stop or station of the integrated public transport system, the date, and the time. Each smart card contains an anonymous code in our data, which allows us to reconstruct users' daily movements.

The data have some limitations. We do not have information on exits, which will provide the complete trip of each user. However, given that we have all smart card validations for each user in a day, we assume that the user's full trip is between the first and last validation of a day. Of course, people may use other means of transport (such as taxis, which are commonly employed in Bogotá) on the same day. However, for most users, the different validations in a day will provide a complete enough indication of their mobility.

Our mobility data do not provide the city's total flows in a day because we do not consider other transportation means, such as taxis and cars. However, given the volume of users in the transport system, the available data are likely to represent the mobility patterns of Bogotá.

We implement a data cleaning procedure, excluding a small percentage of smart cards with a single validation in the day, consecutive validations at the same stop, validations that appear at the bus garages, and trips with more than 10 smart card validations in the same day, which could be related to workers of the transport system. Eliminating these observations, we end up with around 95\% of the validations of a typical workday. Also, we consider all $143 \mathrm{TM}$ stations in the analysis, and we exclude some SITP stops that are not geolocated. We end up with a total of 6197 stops.

Facebook movement range data. Facebook-Data for Good initiative is a collection of methods for processing Facebook data 
into dynamic spatial-temporal maps that illustrate how populations prepare and respond to a crisis, available at https:// dataforgood.fb.com/tools/disease-prevention-maps/ (Maas et al., 2019). Among numerous data sets, Facebook made publicly available the Movement Range data sets, which have two different metrics: Change in movement and Stay Put. The change in movement metric reflects the average number of level 16 bing tiles $(0.6 \mathrm{~km} \times 0.6 \mathrm{~km})$ that a Facebook user (who enabled his geopositioning) was present during $24 \mathrm{~h}$ relative to the pre-crisis levels. The Stay Put metric measures the fraction of the population that appears to stay within a small area surrounding their home for an entire day. Thus, a stationary user is analogous to staying put or staying at home. In the case of Colombia, the data are available at the municipality scale. For this paper, we use the change in movement metric as a proxy of the reduction in mobility.

Mobility networks. To build the mobility network for each week, we consider Tuesdays, Wednesdays, and Thursdays. We avoid using weekends because our primary interest is in the movement on working days. Mondays and Fridays are omitted since the period includes ten holidays, all on Mondays and Fridays, except on Thursday, April 9. Also, we exclude Fridays because mobility patterns are likely to shift as it is common to observe flows towards meeting and social recreation places outside the city.

Thus, the Bogotá public transport network in a given week $(t)$ is represented by a weighted and directed graph, where nodes correspond to all stops (in both SITP and TM), and the link weight is the number of people that make consecutive validations between a given couple of stops. Therefore, the first validation stop corresponds to the origin $o$ and the successive validation stop to the destination $d$.

We also aggregate mobility data at the UPZ level and represent these flows as a network. To do this, we group all stops by their corresponding UPZ and compute the mobility flows to all other UPZ. The network aggregated to this geographical level allows us to detect the relationships between mobility patterns and other local socioeconomic conditions.

Network statistics. We use node statistics which allow studying nodes' characteristics in terms of connectivity for each week. In general, for a generic weighted network matrix $W$ with its corresponding adjacency matrix $A$, the network statistics for node $i$ are: (i) node out-strength $N S_{i}^{\text {out }}=W_{(i)}$, which measures the total outflows; (ii) node in-strength $N S_{i}^{\text {in }}=W_{(i)}^{\mathrm{T}} \mathbf{1}$, which measures the total inflows; (iii) node out-degree $N D_{i}^{\text {out }}=A_{(i)} \mathbf{1}$, which measures the number of destinations; and, (iv) node in-degree $N D_{i}^{\mathrm{in}}=A_{(i)}^{\mathrm{T}} 1$, which measures the number of origins connecting node $i$; where $\mathbf{1}$ is a vector with ones in all entries; and, $A_{(i)}$ and $W_{(i)}$ are the $i$ rows of $A$ and $W$, correspondingly. Network density is the ratio between the actual number of connections and the potential connections: $\rho=m / n(n-1)$, where $m$ is the number of links and $n$ is the number of nodes.

Gravity model estimations. Let $W_{o d}(t)$ be the mobility flow between origin $o$ and destination $d$, in week $t$. We estimate the following gravity equation:

$$
W_{o d}(t)=\frac{P o p_{o}^{\alpha_{1}} P o p_{d}^{\alpha_{2}}}{D_{o d}^{\alpha_{3}}} \exp \left\{x_{o d}(t) \cdot \beta\right\} \eta_{o d}(t)
$$

where

$$
x_{o d}(t)=\left\{X_{o}, X_{d}, \tau_{t}\right\}
$$

$o, d=1, \ldots, N ; P o p_{o}$ is the population at location $o$ and $P o p_{d}$ is the population at location $d ; D_{o d}$ is the geographical distance between locations $o$ and $d ; X=\{$ SES, Informality, Poverty $\}$ is a vector of socioeconomic indicators, including the SES, the share of informal workers, and the level of multidimensional poverty of the location; $\tau_{t}$ is a set of weekly time dummies; and $\eta_{o d}$ is the estimation error, for which we assume that $E\left[\eta_{o d} \mid P_{o p_{o}}, P_{o p_{d}}\right.$, $\left.D_{o d}, \ldots\right]=1$. There are different econometric techniques to estimate Eq. (1). Simple ordinary least squares (OLS) could be applied to the log-linearised equation. However, the estimation requires special treatment of heteroskedasticity (non-linearity) and zero-valued flows (Santos Silva and Tenreyro, 2006). Thus, to deal with these methodological challenges, we implement a Poisson estimation method, which has shown quite satisfactory goodness of fit compared to other econometric techniques to describe the network's properties (Dueñas and Fagiolo, 2013, 2014).

\section{Data availability}

The supported data sources are publicly available, and their sources are presented in the "Methods" section. Additional information regarding the analysis can be obtained from the corresponding author upon request.

Received: 4 October 2020; Accepted: 1 April 2021; Published online: 22 April 2021

\section{References}

Ahmed F, Ahmed N, Pissarides C, Stiglitz J (2020) Why inequality could spread covid-19. Lancet Public Health 5(5):e240

Ault JK, Spicer A (2020) The formal institutional context of informal entrepreneurship: a cross-national, configurational-based perspective. Res Policy 104160

Badr H, Du H, Marshall M, Dong E, Squire M, Gardner L (2020) Association between mobility patterns and COVID-19 transmission in the USA: a mathematical modelling study. Lancet Infect Dis 20(11):1247-1254

Béland LP, Brodeur A, Wright T (2020) The short-term economic consequences of Covid-19: exposure to disease, remote work and government response. IZA Discussion Paper

Benítez MA, Velasco C, Sequeira AR, Henríquez J, Menezes FM, Paolucci F (2020) Responses to COVID-19 in five Latin American countries. Health Policy Technol 9(4):525-559

Bernal R (2009) The informal labor market in Colombia: identification and characterization. Rev Desarr Soc 63(2009), 145-208. https://doi.org/10.13043/ dys.63.4.

Blundell R, Dias MC, Joyce R, Xu X (2020) COVID-19 and inequalities. Fiscal Stud 41(2):291-319

Bonaccorsi G, Pierri F, Cinelli M, Flori A, Galeazzi A, Porcelli F, Schmidt AL, Valensise C, Scala A, Quattrociocchi W et al. (2020) Economic and social consequences of human mobility restrictions under COVID-19. Proc Natl Acad Sci USA 117(27):15530-15535

Buckee C, Balsari S, Chan J, Crosas M, Dominici F, Gasser U, Grad Y, Grenfell B, Halloran E, Kraemer M et al. (2020) Aggregated mobility data could help fight COVID-19. Science 368(6487):145

Chinazzi M, Davis JT, Ajelli M, Gioannini C, Litvinova M, Merler S, Piontti APY, Mu K, Rossi L, Sun K et al. (2020) The effect of travel restrictions on the spread of the 2019 novel coronavirus (COVID-19) outbreak. Science 368 (6489):395-400

Coelho F, Lana R, Cruz O, Villela D, Bastos L, Pastore APY, Davis J, Vespignani A, Codeco C, Gomes M (2020) Assessing the spread of COVID-19 in Brazil mobility, morbidity and social vulnerability. PLoS ONE 15(9):e0238214

DANE (2020a) Boletín Técnico. Medida de pobreza multidimensional municipal. https://www.dane.gov.co/files/investigaciones/condiciones_vida/pobreza/ 2018/informacion-censal/nota-metodologia-censal-pobreza-municipal-2018. pdf

DANE (2020b) Nota metodológica. Índice de vulnerabilidad por manzana. Con el uso de variables demográficas y comorbilidades. https://www.dane.gov.co/ files/comunicados/Nota_metodologica_indice_de_vulnerabilidad.pdf

del Rio-Chanona RM, Mealy P, Pichler A, Lafond F, Farmer JD (2020) Supply and demand shocks in the COVID-19 pandemic: an industry and occupation perspective. Oxford Rev Econ Policy 36(Suppl_1):S94-S137 
Dueñas M, Fagiolo G (2013) Modeling the international-trade network: a gravity approach. J Econ Interact Coord 8(1):155-178

Dueñas M, Fagiolo G (2014) Global trade imbalances: a network approach. Adv Complex Syst 17(03n04):1450014

Fraiberger SP, Astudillo P, Candeago L, Chunet A, Jones NK, Khan MF, Lepri B, Gracia NL, Lucchini L, Massaro E, et al. (2020) Uncovering socioeconomic gaps in mobility reduction during the COVID-19 pandemic using location data. Preprint at arXiv:2006.15195

Gallego J, Montoya S, Sepúlveda C (2016) Effect of socio-economic stratification on house value in Bogotá. CAF Working paper (2016/19)

Gao S, Rao J, Kang Y, Liang Y, Kruse J (2020) Mapping county-level mobility pattern changes in the United States in response to COVID-19. SIGSPATIAL Special 12(1):16-26

Gatto M, Bertuzzo E, Mari L, Miccoli S, Carraro L, Casagrandi R, Rinaldo A (2020) Spread and dynamics of the COVID-19 epidemic in Italy: effects of emergency containment measures. Proc Natl Acad Sci USA 117(19):10484-10491

Gutiérrez D et al. (2020) Determinantes de la distribución espacial de la informalidad laboral en Bogotá. http://www.sdp.gov.co/transparencia/informacioninteres/publicaciones/estudios/determinantes-de-la-distribucion-espacial-deinformalidad-laboral-bogota

Hadjidemetriou GM, Sasidharan M, Kouyialis G, Parlikad AK (2020) The impact of government measures and human mobility trend on COVID-19 related deaths in the UK. Transp Res Interdiscipl Perspect 6:100167

International Labour Organization (ILO) (2014) Trends in informal employment in Colombia: 2009-2013. https://www.ilo.org/wcmsp5/groups/public/--americas/---ro-lima/documents/publication/wcms_245885.pdf

Kraemer M, Yang C-H, Gutierrez B, Wu C-H, Klein B, Pigott D, DuPlessis L, Faria N, Li R, Hanage W et al. (2020) The effect of human mobility and control measures on the COVID-19 epidemic in China. Science 368(6490):493-497

Linka K, Peirlinck M, SahliCostabal F, Kuhl E (2020) Outbreak dynamics of COVID-19 in Europe and the effect of travel restrictions. Comput Methods Biomech Biomed Eng 23(11):710-717

Maas P, Iyer S, Gros A, Park W, McGorman L, Nayak C, Dow P (2019) Facebook disaster maps: Aggregate insights for crisis response andrecovery. In Proceedings of the 16th International Conference on Information Systems for Crisis Response and Management, Franco Z, González JJ, Canós JH (eds). (Information Systems for Crisis Response and Management, Valencia, Spain, 2019), pp. 836-847

Nicola M, Alsafi Z, Sohrabi C, Kerwan A, Al-Jabir A, Iosifidis C, Agha M, Agha R (2020) The socio-economic implications of the coronavirus pandemic (COVID-19): a review. Int J Surg 78:185-193

Oliver N, Lepri B, Sterly H, Lambiotte R, Deletaille S, De Nadai M, Letouzé E, Salah A, Benjamins R, Cattuto C et al. (2020) Mobile phone data for informing public health actions across the COVID-19 pandemic life cycle. Sci Adv 6 (23):eabc0764

Olmos L, Muñoz J (2004) A cellular automaton model for the traffic flow in Bogota. Int J Mod Phys C 15(10):1397-1411

Ramírez Varela A, Pinzón Ortiz JD, González Uribe C, Zapata Bedoya S, Hernández $\mathrm{C}$, Gómez $\mathrm{C}$, Hernández $\mathrm{C}$, Hurtado R, Pineda JD, Frattini AS, Calderón A, Ayala C, Padilla C, Pardo C, Burbano A, Cucunubá Z (2020) COVID-19: Cambios en el sistema de transporte pueden salvar vidas en Bogotá. https://uniandes.edu.co/sites/default/files/asset/document/ bogotadisminucion_de_acceso_a_sistema_transmilenio_pre_cuarentena_0. pdf

Santos Silva J, Tenreyro S (2006) The log of gravity. Rev Econ Stat 88(4):641-658

Schlosser F, Maier BF, Jack O, Hinrichs D, Zachariae A, Brockmann D (2020) Covid-19 lockdown induces disease-mitigating structural changes in mobility networks. Proc Natl Acad Sci USA 117(52):32883-32890
Secretaría Distrital de Desarrollo Económico (2020) Informalidad Laboral Fuerte Bogotá D.C. https://datosabiertos.bogota.gov.co/dataset/informalidad-laboralfuerte-bogota-d-c\#

Secretaría Distrital de Planeación (2017) Encuesta multipropósito. http://www.sdp. gov.co

Transmilenio SA (2020) Estadísticas de oferta y demanda del Sistema Integrado de Transporte Público-SITP, No 64. https://www.transmilenio.gov.co/ publicaciones/149180/estadisticas-de-oferta-y-demanda-del-sistemaintegrado-de-transporte-publico-sitp/

Uribe-Mallarino C (2008) Estratificación social en Bogotá: de la política pública a la dinámica de la segregación social. Univ Humanís (65), 139-171

Weill JA, Stigler M, Deschenes O, Springborn MR (2020) Social distancing responses to COVID-19 emergency declarations strongly differentiated by income. Proc Natl Acad Sci USA 117(33):19658-19660

World Bank (2020) Global economic prospects. World Bank, Washington

Xu Y, Olmos LE, Abbar S, González MC (2020) Deconstructing laws of accessibility and facility distribution in cities. Sci Adv 6(37):eabb4112

\section{Acknowledgements}

We thank Diana C. Gutiérrez for kindly providing us with the data set on informal work.

\section{Author contributions}

All the authors contributed to the conception and design of the work, the analysis and interpretation of data, the draft of the work and its critical review. They have all approved the version to be published.

\section{Competing interests}

The authors declare no competing interests.

\section{Additional information}

Supplementary information The online version contains supplementary material available at https://doi.org/10.1057/s41599-021-00775-0.

Correspondence and requests for materials should be addressed to M.D.

Reprints and permission information is available at http://www.nature.com/reprints

Publisher's note Springer Nature remains neutral with regard to jurisdictional claims in published maps and institutional affiliations.

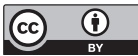

Open Access This article is licensed under a Creative Commons Attribution 4.0 International License, which permits use, sharing, adaptation, distribution and reproduction in any medium or format, as long as you give appropriate credit to the original author(s) and the source, provide a link to the Creative Commons license, and indicate if changes were made. The images or other third party material in this article are included in the article's Creative Commons license, unless indicated otherwise in a credit line to the material. If material is not included in the article's Creative Commons license and your intended use is not permitted by statutory regulation or exceeds the permitted use, you will need to obtain permission directly from the copyright holder. To view a copy of this license, visit http://creativecommons.org/ licenses/by/4.0/

(C) The Author(s) 2021 